GUT MOTILITY

\title{
PEG 3350 (Transipeg) versus lactulose in the treatment of childhood functional constipation: a double blind, randomised, controlled, multicentre trial
}

\section{W Voskuijl, F de Lorijn, W Verwijs, P Hogeman, J Heijmans, W Mäkel, J Taminiau, M Benninga}

See end of article for authors' affiliations

Correspondence to: Dr W P Voskuiil, Department of Paediatric Gastroenterology and Nutrition, Room C2-312, Academic Medical Centre, Meibergdreef 9, 1105

AZ Amsterdam,

the Netherlands;

w.p.voskuii|@amc.nl

Revised version received 6 April 2004

Accepted for publication 13 April 2004
Background: Recently, polyethylene glycol (PEG 3350) has been suggested as a good alternative laxative to lactulose as a treatment option in paediatric constipation. However, no large randomised controlled trials exist evaluating the efficacy of either laxative.

Aims: To compare PEG 3350 (Transipeg: polyethylene glycol with electrolytes) with lactulose in paediatric constipation and evaluate clinical efficacy/side effects.

Patients: One hundred patients (aged 6 months-15 years) with paediatric constipation were included in an eight week double blinded, randomised, controlled trial.

Methods: After faecal disimpaction, patients $<6$ years of age received PEG 3350 (2.95 g/sachet) or lactulose $(6 \mathrm{~g} /$ sachet) while children $\geqslant 6$ years started with 2 sachets/day. Primary outcome measures were: defecation and encopresis frequency/week and successful treatment after eight weeks. Success was defined as a defecation frequency $\geqslant 3 /$ week and encopresis $\leqslant 1$ every two weeks. Secondary outcome measures were side effects after eight weeks of treatment.

Results: A total of 91 patients (49 male) completed the study. A significant increase in defecation frequency (PEG 3350: 3 pre $v 7$ post treatment/week; lactulose: 3 pre $v 6$ post/week) and a significant decrease in encopresis frequency (PEG 3350: 10 pre $v 3$ post/week; lactulose: 8 pre $v 3$ post/week) was found in both groups (NS). However, success was significantly higher in the PEG group (56\%) compared with the lactulose group (29\%). PEG 3350 patients reported less abdominal pain, straining, and pain at defecation than children using lactulose. However, bad taste was reported significantly more often in the PEG group.

Conclusions: PEG $3350(0.26(0.11) \mathrm{g} / \mathrm{kg})$, compared with lactulose $(0.66(0.32) \mathrm{g} / \mathrm{kg})$, provided a higher success rate with fewer side effects. PEG 3350 should be the laxative of first choice in childhood constipation. safely used to rapidly clean the colon of adults and children with refractory constipation. ${ }^{6-9}$ In the long term treatment of constipated adults, PEG was recently shown to be superior to placebo or lactulose with less side effects. ${ }^{10-12}$ There have been indications that low doses of PEG are also a good alternative in the treatment of constipated children. ${ }^{13}{ }^{14}$ However, there are no randomised controlled trials comparing the efficacy of PEG 3350 and lactulose in paediatric constipation. The aim of this study was to compare the clinical efficacy and safety of PEG 3350 (Transipeg; polyethylene glycol with electrolytes) and lactulose in the treatment of functional childhood constipation.

\section{PATIENTS AND METHODS \\ Patients}

Children with constipation were referred by general practitioners, school doctors, and paediatricians. Childhood constipation was defined as having at least two out of four of the following symptoms for the last three months: less than 3 bowel movements per week; encopresis more than once a week; large amounts of stool every 7-30 days (large enough to clog the toilet); and palpable abdominal or rectal mass on physical examination. ${ }^{15}$ Children aged six month to 15 years were included in this study. Children with organic causes for defecation disorders, including Hirschsprung's disease, spina volume expansion in the large intestine. ${ }^{4}$ PEG 3350 appears to be safe as the PEG load recovery in urine is minimal and similar for normal $(0.06 \%)$ and inflammatory bowel subjects $(0.09 \%) .^{5}$ PEG electrolyte solutions were successfully and 
bifida occulta, or hypothyroidism were excluded from the study.

\section{Study design}

The study had a two parallel group, double blind, randomised, prospective, multicentre comparative design and was performed in the Academic Medical Centre (AMC) at Emma Children's Hospital, Amsterdam and two non-teaching hospitals also in the Netherlands. The design was approved by the ethics committees of each centre and conducted in compliance with the Helsinki Declaration. Patients were randomly assigned to receive either lactulose (6 g (sachet)) or PEG 3350 (2.95 g (sachet)). Unlabelled numbered boxes with unlabelled sachets were prepared by the AMC pharmacy and handed out to patients after randomisation. The box contained 180 sachets containing either lactulose $6 \mathrm{~g}$ per sachet or PEG 33502.95 g per sachet.

\section{Run-in phase}

For one week before the study medication was prescribed, defecation and encopresis frequency, stool consistency, and abdominal pain were recorded. The use of oral laxatives was not allowed during this week. At the end of the week, patients received one enema daily for three days to clear any rectal faecal remains. Subjects $\leqslant 6$ years of age received $60 \mathrm{ml}$ Klyx (sodium dioctylsulfosuccinate and sorbitol) while those $>6$ years of age received $120 \mathrm{ml}$ Klyx. Other recorded baseline characteristics were: feelings of bloating, nausea, vomiting, flatulence, painful defecation, and diarrhoea.

\section{Treatment phase}

Based on earlier studies and clinical experience, ${ }^{15}{ }^{16}$ patients aged between six months and six years of age (inclusive) began treatment with one sachet of either PEG 3350 or lactulose per day (2.95 g or $6 \mathrm{~g}$, respectively) while those older than six years of age were given two sachets per day (5.9 g PEG 3350 or $12 \mathrm{~g}$ lactulose). Clinical efficacy and tolerability were recorded in a diary using scores for defecation and encopresis frequency, abdominal pain, feelings of bloating, nausea, vomiting, flatulence, painful defecation, and diarrhoea. Patient assessment of the taste of the treatment was also recorded. Toilet training after each meal (five minutes) was advised and small gifts and praise were used to enhance compliance.

After one week of treatment, efficacy and tolerability, as recorded in the diary, were assessed. If the treatment was considered to be having insufficient effect (persisting symptoms), the dose was increased by one sachet (an additional 2.95 g PEG 3350 or $6 \mathrm{~g}$ lactulose). However, if diarrhoea was reported (overdosing) the original dose was reduced by $50 \%$ (that is, to one sachet or half a sachet). A stimulant laxative was prescribed if the clinical condition had not improved compared with baseline (not successful) with the maximum amount of laxative sachets per day. Clinical evaluation and assessment of diaries was carried out at enrolment and at 1, 2, 4, and 8 weeks, where treatment dose was also appropriately adjusted (fig 1).

\section{Follow up}

After the initial double blind phase, patients were asked to continue in an open label assessment for an additional 18 weeks, in which all patients were treated with PEG 3350. Symptoms continued to be recorded in a diary, with outpatient clinical follow up at 4, 8, and 26 weeks after entering the follow up period, providing a total study time of 34 weeks. If patients were unable to visit the outpatient clinic for follow up, history was obtained by telephone.

\section{Efficacy}

The primary efficacy end points were frequency of stools, frequency of encopresis, and overall treatment success at eight weeks. An increase in defecation frequency was considered to have improved if it rose to three or more times a week while encopresis had to decrease to an incidence of one episode or less every two weeks.

Overall treatment success was defined as three or more bowel movements a week and one encopresis episode or less every two weeks. Stool consistency was also recorded but due to the nature of the parameter and the difficulty in applying semi quantitative values to the categories, statistical analysis of this end point is limited.

\section{Safety}

The incidence of adverse events during the eight weeks of treatment was also documented. Both the incidence and severity of gastrointestinal adverse events were recorded in the diary and assessed at weeks 1, 2, 4, and 8 of the double blind period of the trial, with a three point scale: $0=$ no gastrointestinal symptoms present, $\mathrm{l}=$ gastrointestinal symptoms present to some extent, and $2=$ gastrointestinal symptoms present.

\section{Statistics}

It was estimated that a total sample of 90 patients would be adequate to show a difference of at least $30 \%$ more success at eight weeks using PEG 3350 compared with lactulose, with a two tailed alpha level of 0.05 with a power of $80 \%$. The analysis was performed as a per protocol analysis, including those subjects that completed the double blind treatment period. Values are expressed as mean (SD). Comparisons between the two treatment groups were performed using Student's $t$ tests or non-parametric Mann-Whitney $U$ tests according to the distribution of values, and $\chi^{2}$ tests. A p value of $<0.05$ was considered significant.

Logistic regression was applied in order to detect variables prognostic for success. The following variables were included in the logistic regression: age at enrolment, number of
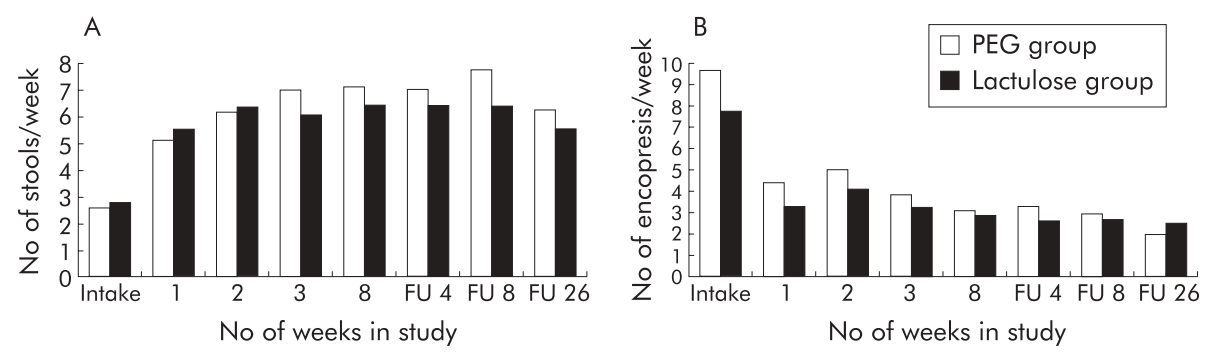

Figure 1 Defecation frequency (A) and encopresis frequency (B) in the polyethylene glycol 3350 (PEG) group and lactulose group. There was no significant difference between the two patient groups with respect to these two parameters at all time points. Note: all patients openly switched to PEG 3350 after the study period of eight weeks. FU, follow up. 
Table 1 Baseline characteristics

\begin{tabular}{lll}
\hline & PEG 3350 & Lactulose \\
\hline No of patients at randomisation & 50 & 50 \\
Age (y) (mean (SD)) & $6.5(3.2)$ & $6.5(3.4)(p=0.9)$ \\
Sex (M/F) & $27 / 23$ & $28 / 22(p=0.7)$ \\
No of patients not withdrawn & 46 & 45 \\
Age (y) (mean (SD)) & $6.5(3.2)$ & $6.6(3.4)$ \\
Sex (M/F) & $24 / 22$ & $25 / 20$ \\
Inclusion criteria (No of patients) & 32 & 30 \\
Defecation frequency <3/week & 29 & 30 \\
Encopresis > 1/week & 30 & 25 \\
Large amounts of stool & 24 & 26 \\
Faecal impaction & 4 & 5 \\
Premature withdrawal & 2 & 2 \\
Lost to follow up & 0 & 2 \\
Helicobacter positive & 1 & 1 \\
Reason unknown & 1 & 0 \\
Bad palatability of study medication & & \\
\hline PEG, polyethylene glycol 3350. & &
\end{tabular}

months treatment before enrolment, composite variable of encopresis and soiling, family history, and sex.

\section{RESULTS}

Between 1 May 2001 and 1 May 2002, 100 patients (aged 6 months-15 years) with childhood functional constipation were included in the study. The majority of patients (76) were treated in the outpatient clinic of our tertiary hospital; 24 patients were included and treated in the two nonteaching hospitals. As shown in table l, no significant differences were found with respect to demographic data and recorded baseline characteristics between the two treatment groups. There were nine dropouts due to various reasons (see table 1). Therefore, the final data set consisted of a total of 91 patients (46 in the PEG group and 45 in the lactulose group). As no withdrawals occurred for efficacy reasons, data analysis is based on these 91 patients (per protocol analysis).

\section{Clinical efficacy at eight weeks}

Compared with intake, a significant increase in mean defecation frequency/week and a significant decrease in mean encopresis frequency/week were found at eight weeks in both groups (table 2). There was no significant difference between the two patient groups with respect to these two parameters at $1,2,4$, and 8 weeks of the study (see fig 1 , table 2 ). Dividing patients in accordance with age $(<6$ years and $\geqslant 6$ years), the same results were found with respect to defecation and encopresis frequency at eight weeks (see table 2).

\section{Success percentages}

A significantly higher number of patients in the PEG group were successfully treated after eight weeks of treatment compared with the lactulose group (PEG 56\% v lactulose 29\%; $\mathrm{p}=0.02)$. This difference was irrespective of age $(<6$ years and $\geqslant 6$ years). Success rates did not change in the PEG 3350 treatment group during the follow up period (see table 2). In the group of children on lactulose, who openly switched to PEG 3350 at the end of the eight week study period, a significant increase in success rate was found $(29 \%$ to $47 \%$; $\mathrm{p}=0.05)$ after 26 weeks of follow up.

A total of 26 patients were treated with laxatives for at least one year prior to the start of the study. Of these patients, $14 \%$ and $33 \%$, respectively, were treated successfully with lactulose or PEG 3350 (NS). In contrast, in those children treated for less than one year, a significant difference in success was found between patients treated with PEG 3350 $(63 \%)$ or lactulose $(31 \%)(p=0.02)$.

\section{Prognostic variables for success}

In multivariate analysis to identify predictors of success, using a logistic regression model, the factors age at enrolment

Table 2 Clinical parameters, success percentages, and dosage of laxative (Student's $t$ test) in the polyethylene glycol 3350 (PEG) and lactulose groups

\begin{tabular}{|c|c|c|c|c|c|c|}
\hline \multirow[b]{2}{*}{ Defecation frequency/week } & \multicolumn{2}{|l|}{ PEG 3350} & \multirow[b]{2}{*}{ p Value } & \multicolumn{2}{|l|}{ Lactulose } & \multirow[b]{2}{*}{ p Value } \\
\hline & Intake & 8 weeks & & Intake & 8 weeks & \\
\hline All age groups & $2.59(3.34)$ & $7.12(5.14)$ & $<0.01$ & $2.75(3.08)$ & $6.43(5.18)$ & $<0.01$ \\
\hline$<6 y$ & $1.39(1.09)$ & $7.18(4.70)$ & $<0.01$ & $1.76(1.26)$ & $5.22(3.92)$ & $<0.01$ \\
\hline$\geqslant 6 y$ & $3.69(4.25)$ & $7.08(5.57)$ & $<0.01$ & $3.83(4.04)$ & $7.70(6.07)$ & 0.01 \\
\hline Encopresis frequency/week & Intake & 8 weeks & & Intake & 8 weeks & \\
\hline All age groups & $9.70(14.98)$ & $3.11(5.41)$ & $<0.01$ & $7.73(11.17)$ & $2.84(3.59)$ & $<0.01$ \\
\hline$<6 y$ & 14.25 (19.69) & $3.54(5.61)$ & 0.01 & $7.54(14.02)$ & $3.56(4.51)$ & 0.172 \\
\hline$\geqslant 6 y$ & $5.52(6.83)$ & 2.72 (5.34) & 0.07 & $7.93(7.18)$ & $2.08(2.14)$ & 0.01 \\
\hline \multicolumn{7}{|l|}{ Success percentages $(95 \% \mathrm{Cl})$} \\
\hline At 8 weeks & $56 \%(39-70)$ & & & $29 \%(16-44)$ & & 0.02 \\
\hline FU 4 weeks & $53 \%(36-68)$ & & & $36 \%(21-53)$ & & 0.18 \\
\hline FU 8 weeks & $54 \%(37-71)$ & & & $41 \%(26-58)$ & & 0.36 \\
\hline FU 26 weeks & $63 \%(46-76)$ & & & $47 \%(32-62)$ & & 0.13 \\
\hline \multicolumn{7}{|l|}{ Medication (sachet/day) } \\
\hline At 8 weeks & $1.99(0.3)$ & & & $2.4(0.4)$ & & 0.03 \\
\hline
\end{tabular}

FU, follow up; $95 \% \mathrm{Cl}, 95 \%$ confidence interval.

The lactulose group experienced a significant increase in success after changing to PEG at the end of the intervention period (29\%) compared with follow up at 26 weeks $(47 \%)(p=0.05)$. 


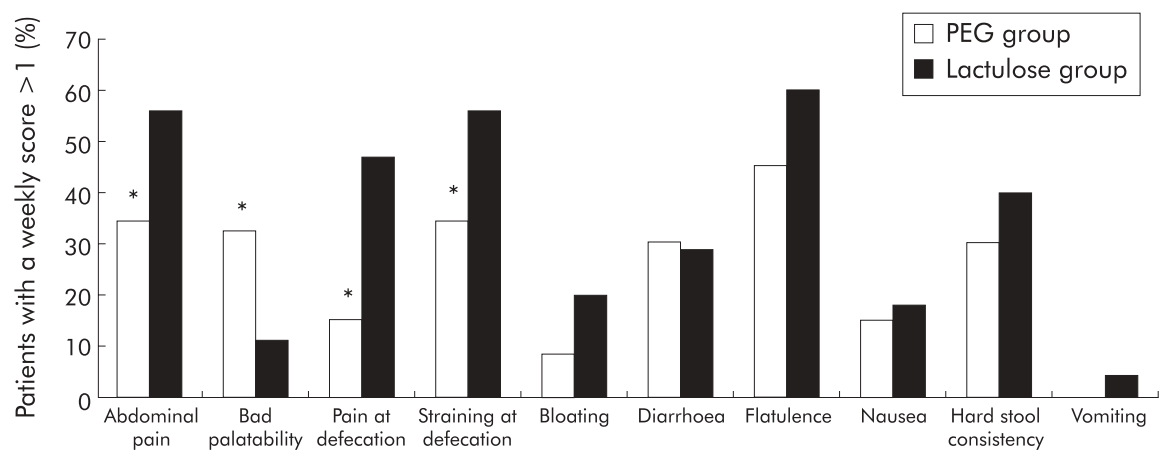

Figure 2 Side effects after eight weeks of study in the polyethylene glycol 3350 (PEG) group and the lactulose group. ${ }^{*} \mathrm{p}<0.05$. and family history did not significantly contribute to success of the treatment. However, the overall success rate after the eight week treatment period was higher in female patients $(p=0.025)$, lower in children who were treated for more than one year before enrolment in the present study $(p=0.008)$, and lower in those children with higher frequencies of encopresis at enrolment $(p=0.017)$.

\section{Side effects}

During the eight week study period there were no serious or significant adverse events recorded. Figure 2 shows that significantly more adverse events were reported by patients using lactulose compared with patients on PEG. However, significantly more children complained of bad palatability of PEG compared with those receiving lactulose. This resulted in the premature withdrawal of one patient in the PEG group. Serious side effects were not reported in either group.

\section{Treatment dosage}

The mean PEG dosage at four weeks and eight weeks for children who clinically improved was 5.07 (1.36) g/day and $5.40(2.30) \mathrm{g} /$ day, respectively. In the lactulose group, doses associated with improvement were 11.52 (4.56) g/day (1.9 sachets) and 13.86 (6.66) g/day (2.3 sachets) at four and eight weeks, respectively. Dividing clinically successful patients (after eight weeks) into those $<6$ years and those $\geqslant 6$ years, the optimal dose of PEG was $0.26(0.13) \mathrm{g} / \mathrm{kg} / \mathrm{day}$ and $0.26(0.07) \mathrm{g} / \mathrm{kg} /$ day, respectively. The optimal dose of lactulose in clinically successful patients $<6$ years and $\geqslant 6$ years was $0.96(0.45) \mathrm{g} / \mathrm{kg} /$ day and $0.45(0.27) \mathrm{g} / \mathrm{kg} /$ day, respectively.

In the PEG group, mean stool frequency increased by 1.89 / week $(p=0.03)$ after an increase in the dose with one sachet during the clinical visit. No increase in stool frequency was found in the lactulose group after increasing the dose. Nine children in the PEG 3350 group and 10 in the lactulose group needed an additional stimulant laxative (bisacodyl) (NS).

\section{DISCUSSION}

In this randomised, controlled, double blind study in children with constipation, we found that compared with baseline, both PEG 3350 and lactulose resulted in a significant increase in defecation frequency and a significant decrease in encopresis frequency after eight weeks of treatment. Clinical improvement was irrespective of age at intake (that is, $<6$ years and $\geqslant 6$ years). Follow up at six months showed a comparable increase in defecation frequency and decrease in encopresis frequency in both groups. During the intervention and open label follow up period, these clinical parameters were not significantly different between the two treatment groups.

PEG 3350 however was associated with a significantly higher success rate $(56 \%)$ than lactulose $(29 \%)$. Similar success rates for PEG 3350 were found by Loening-Baucke, both after the intervention period and at six months of follow up. $^{13}$ Comparison with other paediatric studies using PEG 3350 in the treatment of constipation is difficult as no criteria for success were mentioned in these studies. ${ }^{14}{ }^{17}$ A similar success rate for lactulose was reported in an earlier study evaluating the additional effect of biofeedback training (33\%) in children with chronic constipation. ${ }^{15}$ In this latter study, a significant increase in success was found $(52 \%)$ at six months of follow up compared with the success rate at the end of the intervention period..$^{15}$ It is unclear if the similar significant increase in success in the group of children who openly switched to PEG 3350 at the end of the eight week study period is the result of PEG 3350 or of our intensive follow up programme.

In accordance with previous studies, a low encopresis frequency and a short period of treatment before enrolment were associated with successful treatment outcome. ${ }^{18} \mathrm{~A}$ longer period of treatment suggests an early age of onset of constipation, indicating a primarily organic underlying mechanism, in contrast with children who have shown normal defecation for many years before experiencing constipation. Our study shows that children with encopresis are more difficult to treat, underscoring the necessity of long lasting laxative (oral and/or rectal) treatment. Conflicting data exist concerning the relation between success and relevant cofactors such as sex, positive family history, clinical parameters, anorectal parameters (abnormal contraction of the external sphincter), histological parameters (decreased number of interstitial cells of Cajal, reduced ganglionic density, and size), and symptoms before intake. ${ }^{18-25}$

In accordance with others who have evaluated PEG 3350 in the treatment of children with constipation, only mild side effects were reported. ${ }^{6}{ }^{13} 1426$ In contrast with an adult study comparing PEG 3350 with lactulose, abdominal pain, straining on defecation, and pain during defecation occurred significantly less often in those children receiving PEG 3350 compared with children receiving lactulose. ${ }^{11}$ Surprisingly, flatulence did not differ between the two treatment groups, as has been reported by others. ${ }^{10}{ }^{11}$ Therefore, mechanisms other than colonic fermentation must also play a role in abdominal pain and production of flatus in these children, such as an osmotic effect or an increase in colonic motility. ${ }^{10} 2728$ We have no explanation as to why children receiving lactulose experienced significantly more straining and pain during defecation than children receiving PEG 3350. One can speculate that the dose of lactulose was too low. However, no difference was found in stool consistency or the prevalence of diarrhoea, suggesting an adequate dosage of lactulose.

In the Netherlands, PEG 3350 without electrolytes (Miralax; Braintree Laboratories, Braintree, Massachusetts, USA) is not available. Although a significant number of children did not like the salty taste of PEG 3350, compliance 
was high. Only one child prematurely finished the study because of bad palatability.

The mean effective dose of PEG 3350 for the treatment of constipation in children $\leqslant 6$ years and older than 6 years was $0.26(0.13) \mathrm{g} / \mathrm{kg} / \mathrm{day}$ and $0.26(0.07) \mathrm{g} / \mathrm{kg} /$ day, respectively. Although the dose administered was lower than that used in other studies in children with constipation, comparable effects on clinical parameters were found..$^{13}{ }^{14}{ }^{17}$ In contrast with these studies, we used PEG-ELS with additional electrolytes (iso-osmotic), which may exhibit a more potential osmotic effect than PEG without electrolytes (hypoosmotic) ${ }^{29}$

In both treatment groups, approximately $20 \%$ of patients needed additional stimulant laxatives during the intervention period. This is in contrast with results of Attar and colleagues $^{11}$ who showed that significantly less (adult) patients with PEG 3350 needed stimulant laxatives (suppositories or micro-enemas) compared with lactulose. For practical purposes, we were not able to prescribe a higher dose, as suggested by others, ${ }^{28}$ as the maximal amount of PEG 3350 in this study was $8.85 \mathrm{~g} /$ day.

In conclusion, the results of this study showed that PEG 3350 was more effective with fewer side effects than lactulose in the treatment of childhood constipation. Therefore, PEG 3350 should replace lactulose as the first treatment option in children with mild and severe constipation. The optimal dose of PEG 3350 for children younger than six years is 0.26 $(0.13) \mathrm{g} / \mathrm{kg} /$ day and $0.26(0.07) \mathrm{g} / \mathrm{kg} /$ day for those older than six years.

\section{Authors' affiliations}

W Voskuijl, F de Lorijn, J Heijmans, J Taminiau, M Benninga,

Department of Paediatric Gastroenterology and Nutrition, Emma Children's Hospital, Academic Medical Centre, Amsterdam, the Netherlands

W Verwijs, Department of Paediatrics, Hofpoort Ziekenhuis, Woerden, the Netherlands

P Hogeman, Department of Paediatrics, Meander Medisch Centrum, Amersfoort, the Netherlands

W Mäkel, MediServ BV/Clinical Research facilities BV, Schaijk, the Netherlands

\section{REFERENCES}

1 Liptak GS, Baker SS, Colletti RB, et al. Constipation. In: Moyer VA, Elliot EJ, Davis RL, et al, eds. Evidence based paediatrics and child health. Manchester: BMJ Books, 2000:264-72.

2 Candelli M, Nista EC, Zocco MA, et al. Idiopathic chronic constipation pathophysiology, diagnosis and treatment. Hepatogastroenterology 2001;48:1050-7

3 Whitehead WE, Chaussade S, Corazziari E, et al. Report of an international workshop on management of constipation. Gastroenterol Int 1991;4:99-113.

4 Schiller LR, Emmett M, Santa Ana CA, et al. Osmotic effects of polyethylene glycol. Gastroenterology 1988;94:933-41.
5 Brady CE III, DiPalma JA, Morawski SG, et al. Urinary excretion of polyethylene glycol 3350 and sulfate after gut lavage with a polyethylene glycol electrolyte lavage solution. Gastroenterology 1986;90:1914-18.

6 Andorsky RI, Goldner F. Colonic lavage solution (polyethylene glycol electrolyte lavage solution) as a treatment for chronic constipation: a doubleblind, placebo-controlled study. Am J Gastroenterol 1990;85:261-5.

7 Ingebo KB, Heyman MB. Polyethylene glycol-electrolyte solution for intestinal clearance in children with refractory encopresis. A safe and effective therapeutic program. Am J Dis Child 1988;142:340-2.

8 Sondheimer JM, Sokol RJ, Taylor SF, et al. Safety, efficacy, and tolerance of intestinal lavage in paediatric patients undergoing diagnostic colonoscopy. J Pediatr 1991;119:148-52.

9 Tolia V, Lin CH, Elitsur Y. A prospective randomized study with mineral oil and oral lavage solution for treatment of faecal impaction in children. Aliment Pharmacol Ther 1993.7:523-9.

10 Corazziari E, Badiali D, Habib Fl, et al. Small volume isosmotic polyethylene glycol electrolyte balanced solution (PMF-100) in treatment of chronic nonorganic constipation. Dig Dis Sci 1996;41:1636-42.

11 Attar A, Lemann M, Ferguson A, et al. Comparison of a low dose polyethylene glycol electrolyte solution with lactulose for treatment of chronic constipation. Gut 1999;44:226-30

12 DiPalma JA, DeRidder PH, Orlando RC, et al. A randomized, placebocontrolled, multi centre study of the safety and efficacy of a new polyethylene glycol laxative. Am J Gastroenterol 2000;95:446-50.

13 Loening-Baucke V. Polyethylene glycol without electrolytes for children with constipation and encopresis. J Pediatr Gastroenterol Nutr 2002;34:372-7.

14 Pashankar DS, Bishop WP. Efficacy and optimal dose of daily polyethylene glycol 3350 for treatment of constipation and encopresis in children. J Pediatr $2001 ; 139: 428-32$

15 van der Plas RN, Benninga MA, Büller HA, et al. Biofeedback training in treatment of childhood constipation: a randomised controlled study. Lancet 1996:348:776-80.

16 Dupont C, Ammar F, Leluyer B, et al. PEG 4000 in constipated children (6 months-15 years): a dose determination study. Gastroenterology 2000;118:4-1.

17 Gremse DA, Hixon J, Crutchfield A. Comparison of polyethylene glycol 3350 and lactulose for treatment of chronic constipation in children. Clin Pediatr (Phila) 2002;41:225-9.

18 van Ginkel R, Reitsma JB, Büller HA, et al. Childhood constipation: Longitudinal follow-up beyond puberty. Gastroenterology 2003;125:357-63.

19 Loening-Baucke V. Factors determining outcome in children with chronic constipation and faecal soiling. Gut 1989;30:999-1006.

20 Loening-Baucke V. Biofeedback treatment for chronic constipation and encopresis in childhood: long-term outcome. Pediatrics 1995;96:105-10.

21 Loening-Baucke V. Persistence of chronic constipation in children after biofeedback treatment. Dig Dis Sci 1991;36:153-60.

22 Borowitz SM, Sutphen J, Ling W, et al. Lack of correlation of anorectal manometry with symptoms of chronic childhood constipation and encopresis. Dis Colon Rectum 1996;39:400-5.

23 Sutphen J, Borowitz S, Ling W, et al. Anorectal manometric examination in encopretic-constipated children. Dis Colon Rectum 1997;40:1051-5.

24 Staiano A, Andreotti MR, Greco L, et al. Long-term follow-up of children with chronic idiopathic constipation. Dig Dis Sci 1994;39:561-4.

25 Wedel T, Spiegler J, Soellner S, et al. Enteric nerves and interstitial cells of Cajal are altered in patients with slow-transit constipation and megacolon. Gastroenterology 2002;123:1459-67.

26 Pashankar DS, Loening-Baucke V, Bishop WP. Safety of polyethylene glycol 3350 for the treatment of chronic constipation in children. Arch Pediatr Adolesc Med 2003;157:661-4.

27 Hammer HF, Santa Ana CA, Schiller LR, et al. Studies of osmotic diarrhoea induced in normal subjects by ingestion of polyethylene glycol and lactulose. J Clin Invest 1989:84:1056-62.

28 Youssef NN, Peters JM, Henderson W, et al. Dose response of PEG 3350 for the treatment of childhood faecal impaction. J Pediatr 2002;141:410-14.

29 Chaussade S, Minic M. Comparison of efficacy and safety of two doses of two different polyethylene glycol-based laxatives in the treatment of constipation. Aliment Pharmacol Ther 2003;17:165-72. 